\title{
Differential Influence of Associative and Nonassociative Learning Mechanisms on the Responsiveness of Prefrontal and Accumbal Dopamine Transmission to Food Stimuli in Rats Fed Ad Libitum
}

\author{
Valentina Bassareo and Gaetano Di Chiara \\ Department of Toxicology and Consiglio Nazionale delle Ricerche, Centre for Neuropharmacology, University of Cagliari, \\ 09126 Cagliari, Italy
}

Feeding a novel food (Fonzies) to rats fed ad libitum with standard food increased extracellular dopamine (DA) in the medial prefrontal cortex (PFCX) and in the medial nucleus accumbens (NAc). Previous Fonzies feeding, although it did not affect the increase of extracellular DA in the PFCX in response to Fonzies feeding, blunted that increase in the NAc (habituation); recovery from habituation in the NAc was complete $5 \mathrm{~d}$ after previous Fonzies feeding. Predictive association of an otherwise neutral stimulus extrinsic to Fonzies (empty plastic box) with Fonzies feeding resulted in the acquisition by the stimulus of the property to elicit incentive responses directed toward the stimulus and to increase extracellular DA in the PFCX. However, the same stimulus, or a more complex stimulus including intrinsic stimuli (Fonzies-filled plastic box), failed to acquire the ability to modify extracellular DA in the NAc.
Pseudoconditioning, i.e., nonpredictive association of the extrinsic stimulus (empty box) with Fonzies feeding, did not result in acquisition by the stimulus of the property to elicit incentive responses and to increase extracellular DA in the PFCX. Repeated nonreinforced presentation of previously conditioned extrinsic stimuli (empty box) resulted in extinction of the property to elicit incentive responses and to increase extracellular DA in the PFCX. These results indicate that in rats fed ad libitum, phasic activation of mesocortical and mesolimbic DA systems by motivational stimuli is differentially influenced by associative (conditioning) and nonassociative (habituation) learning mechanisms and is differentially related to acquisition and expression of incentive motivation.

Key words: DA; nucleus accumbens; prefrontal cortex; feeding; motivation; incentive; conditioning
A large body of evidence obtained from experimental manipulation of central DA transmission by drugs and lesions points to an important role of brain DA in behavior motivated by conventional (e.g., food, water, sex) and unconventional (electrical brain stimulation, drugs, and substances of abuse) reinforcers (Wise, 1982; Beninger, 1983; Robbins et al., 1989; Le Moal and Simon, 1991; Phillips et al., 1991; Salamone, 1992; Di Chiara, 1995). More recently, the introduction of in vivo monitoring techniques such as brain microdialysis (Ungerstedt, 1984; Westerink et al., 1987; Di Chiara, 1990), voltammetry (Kissinger et al., 1973; Marsden et al., 1984; Stamford, 1986), and single-unit recording in behaving animals (Miller et al., 1981; Steinfels et al., 1981; Schultz, 1992) has provided information on the conditions for phasic activation of DA neurons and DA transmission and its relationship with behavior.

DA neurons are phasically responsive to unconditioned motivational stimuli (Schultz, 1992; Fibiger, 1993; Di Chiara, 1995; Westerink, 1996). Physiological state (e.g., hunger, thirst) seems to be a major determinant of this responsiveness (Church et al., 1987; Hernandez and Hoebel, 1988a,b; Radhakishun et al., 1988;

\footnotetext{
Received July 22, 1996; revised Nov. 4, 1996; accepted Nov. 5, 1996.

This study was made with funds from Consiglio Nazionale delle Ricerche, Progetto finalizzato "Medicina Preventiva," sottoprogetto "Stress," from the European Commission, Biomed Project BM H1-CT92-1086, and from Ministero dell'Università e della Ricerca Scientifica $40 \%$ and $60 \%$, respectively. Preliminary accounts of this work were presented at the European Neuroscience Association Meeting (Amsterdam, 1995) and at the European Behavioral Pharmacology Society Meeting (Cagliari, Italy, 1996). We acknowledge the typing work of Ms. Adelaide Marchioni.

Correspondence should be addressed to Dr. Gaetano Di Chiara, Dipartimento di Tossicologia, Viale A. Diaz 182, 09126 Cagliari, Italy.

Copyright (C) 1997 Society for Neuroscience 0270-6474/97/170851-11\$05.00/0
}

Yoshida et al., 1992; Young et al., 1992; Inoue et al., 1993; Westerink et al., 1994; Wilson et al., 1995). However, because physiological need states are known to result in a generalized increase of the impact of motivational stimuli, including those unrelated to the deprived reward (Bindra, 1968), the specificity of these effects is unclear.

Appetitive conditioned stimuli that predict the presentation of unconditioned motivational stimuli can also activate DA transmission, but this property is debated (Phillips et al., 1991, 1993; Fibiger, 1993; Schultz et al., 1993; Wilson et al., 1995; Mirenowicz and Schultz, 1996). Related to the above issue is that of the relationship between changes of DA transmission and preparatory (incentive, appetitive) versus consummatory (rewarding) properties of conventional reinforcers (Blackburn et al., 1987, 1989; Phillips et al., 1991).

A further aspect of these studies relates to the specific DA subsystem being investigated. The rat mesocortical DA neurons project mainly to the PFCX (Thierry et al., 1973; Björklund and Lindvall, 1984; Berger et al., 1991). Although PFCX DA transmission is known to be activated by stress and aversive stimuli (Thierry et al., 1976; Abercrombie et al., 1989; Imperato et al., 1989; Bradberry et al., 1991; Bassareo et al., 1996), very little information is available on the effect of appetitive and rewarding stimuli on mesocortical DA. Apart from a report of an increase of the voltammetric signal for DOPAC in the PFCX in response to feeding and food smell in food-deprived rats (D'Angio and Scatton, 1989), to our knowledge only two studies have investigated by microdialysis the effect of a reward (food in every case) on extracellular DA in the PFCX; one study used food-deprived rats (Hernandez and Hoebel, 1990), whereas in the other a DA 
reuptake inhibitor was included in the dialyzing Ringer (Cenci et al., 1992).

For rats maintained on standard food ad libitum, we have studied by microdialysis the changes in extracellular DA in the PFCX and in the NAc in response to feeding of a palatable food (Fonzies) and to presentation of stimuli conditioned to it. To obtain information on the relationship between phasic changes in DA transmission and motivated behavior, incentive/appetitive and consummatory responses were also recorded (see "Behavioral recording" in Materials and Methods).

\section{MATERIALS AND METHODS}

Subjects and materials. Male Sprague Dawley rats (200-250 gm) were obtained from Charles River (Calco, Italy) and kept six per cage with standard food (MIL topi e ratti, GLP diets, Stefano Morini, S. Polo D'Enza, RE, Italy) and water ad libitum for at least 1 week in the central animal room under constant temperature $\left(23^{\circ} \mathrm{C}\right)$ and humidity $(60 \%)$ and a $12 \mathrm{hr}$ light/dark cycle (lights from 6 A.M. to 6 P.M.).

Fonzies (KP Snack Foods, Germany) is a highly palatable food made of corn flour, hydrogenated vegetable fat, cheese powder, and salt. Fonzies contains $8 \%$ protein, $33 \%$ fat, and $53 \%$ carbohydrates for a caloric value of $541 \mathrm{kCal} / 100 \mathrm{~g}$.

All animal experimentations have been conducted in accordance with the statement revised and approved by the Society for Neuroscience in January 1995 and with the guidelines for care and use of experimental animals of the European Economic Community (86/609; D.L.: 27.01.1992, No. 116).

General procedures. For training, rats were transferred to smaller, individual cages (width, $15 \mathrm{~cm}$; height, $20 \mathrm{~cm}$; length, $20 \mathrm{~cm}$ ) and brought from the main animal room to an adjacent room (training room) under the same conditions of temperature, humidity, and light. All training procedures were performed in this room during the morning (from 10:00 A.M. to 12:00 P.M.), except when specifically indicated. On the day of surgery, the rats were brought to the surgery room where they were anesthetized and implanted with probes. Rats were then brought, while still anesthetized, to another room and placed in large hemispheric bowls (diameter, $50 \mathrm{~cm}$ ) with bedding on the bottom where they spent the night with water and standard food ad libitum. The next day, the microdialysis experiment was performed in the same bowls, except that standard food and water were withdrawn. As a rule, six rats were dialyzed in one afternoon (between 12:00 P.M. and 6:00 P.M.). When the PFCX and the NAc were compared, microdialysis was performed in parallel on a maximum of three rats implanted in the PFCX and three rats implanted in the NAc. Each hemispheric bowl was equipped with a liquid swivel connected to the perfusion pumps and to the rat and was placed into a dark plastic box with a removable cover made of transparent plastic with the appropriate openings for passage of the inlet and outlet tubing to the liquid swivel. The outlet from the swivel was made of a length sufficient to bring the sample outside the box so that samples could be taken manually without disturbing the rat. Fonzies were placed in front of the rat with the aid of a forceps. Care was taken not to touch the food with the hands.

Behavioral recording. Although the terms "incentive" and "appetitive," pertaining to motivated responses, should be considered as synonymous, we used the term appetitive to indicate responses made in the presence of food available for consumption (e.g., latency to eat), whereas the term "incentive" was used to indicate responses in which the food was not immediately available. "Consummatory" refers to eating itself.

The behavior of the rat was recorded on two occasions by an observer not aware of the nature of each experimental group: after Fonzies presentation, in which case latency to eat (appetitive response) and amount of Fonzies eaten (consummatory response) were recorded; and after presentation of the secondary stimulus (plastic box), in which case the incentive response was recorded. The incentive response was distinguished into three patterns of increasing intensity: orienting reaction (the rat directs its snout toward the object stimulus and sniffs at the air in the same direction); approach reaction (the rat moves toward the object stimulus and contacts it with front paws and with the snout while actively sniffing); and consummatory attempts (the rat licks and/or bites the object stimulus). The occurrence of each behavioral pattern was recorded for 40 min subdivided in $5 \mathrm{~min}$ and $5 \mathrm{sec}$ blocks. The results obtained were scored as follows: score 1 , orienting reaction for $1-5$ blocks of $5 \mathrm{sec}$ each; score 2, same behavior for more than 5 blocks of $5 \mathrm{sec}$; score 3 , approach reaction for 1-5 blocks of $5 \mathrm{sec}$ each; score 4 , same behavior for more than 5 blocks of $5 \mathrm{sec}$ each; score 5, consummatory attempts for 1-5 blocks of $5 \mathrm{sec}$ each; and score 6 , same behavior for more than 5 blocks of $5 \mathrm{sec}$ each. The resulting scores were summed up for each $5 \mathrm{~min}$ period.

Brain microdialysis. Concentric dialysis probes with a dialyzing portion of $1.5 \mathrm{~mm}$ were prepared with AN69 fibers (Hospal Dasco, Bologna, Italy), according to the method of Di Chiara et al. (1993) and as modified by Tanda et al. (1996).

Rats were anesthetized i.p. with $100 \mathrm{mg} / \mathrm{kg}$ of ketamine (Ketalar, Parke-Davis) and placed in a stereotaxic apparatus. The skull was exposed, and a small hole was drilled to expose the dura on one side. Probes were aimed at the NAc shell or at the PFCX according to the atlas of Paxinos and Watson (1987) (coordinates: NAc, anterior $=$ +2.5 , lateral $=1.2$, and ventral $=-8.2 ; \mathrm{PFCX}$, anterior $=3.7$, lateral $=0.8$, and ventral $=-4.8$ ).

Experiments were performed on freely moving rats $24 \mathrm{hr}$ after implant of probes. Ringer's solution ( $147 \mathrm{~mm} \mathrm{NaCl}, 2.2 \mathrm{mM} \mathrm{CaCl}_{2}, 4 \mathrm{~mm} \mathrm{KCl}$ ) was pumped through the dialysis probe at a constant rate of $1 \mu \mathrm{l} / \mathrm{min}$. Samples were taken every $10 \mathrm{~min}$ from the NAc and every $20 \mathrm{~min}$ from the PFCX. Dialysate samples $(10 \mu \mathrm{l}$ or $20 \mu \mathrm{l})$ were injected without purification into an HPLC apparatus equipped with a reverse-phase column (LC-18 DB, $15 \mathrm{~cm}, 5-\mu \mathrm{m}$ particle size; Supelco) and a coulometric detector (ESA, Coulochem II, Bedford, MA) to quantitate DA. The first electrode of the detector was set at $+130 \mathrm{mV}$ (oxidation) and the second at $-175 \mathrm{mV}$ (reduction). The composition of the mobile phase was $50 \mathrm{~mm} \mathrm{NaH}_{2} \mathrm{PO}_{4}$, $5 \mathrm{mM} \mathrm{Na}_{2} \mathrm{HPO}_{4}, 0.1 \mathrm{~mm} \mathrm{Na}$-EDTA, $0.5 \mathrm{~mm} n$-octyl sodium sulfate, $15 \%$ (v/v) methanol, $\mathrm{pH}$ 5.50. The mobile phase was pumped with an LKB 2150 pump at a flow rate of $1.0 \mathrm{ml} / \mathrm{min}$. The sensitivity of the assay for DA was 5 fmol per sample.

Histology. At the end of the experiment, rats were transcardially perfused with $100 \mathrm{ml}$ of saline and $500 \mathrm{ml}$ of a $4 \%$ formaldehyde/ $1 \%$ calcium acetate $/ 100 \mathrm{~mm} \mathrm{NaCl}$ solution. The probes were removed, and brains were cut on a Vibratome in serial coronal slices oriented according to the atlas of Paxinos and Watson (1987). The sections were processed for Luxol fast cresyl violet stain. In this manner, the location of the probes was reconstructed and referred to the atlas of Paxinos and Watson (1987).

The following is a specific description of the experiments performed in the present study.

Preliminary trials. Preliminary trials had shown that, when fed ad libitum, rats would eat the standard food in a very inconsistent manner, incompatible with the requirements of an experimental design. Therefore, various foods known to be highly palatable for humans were tested. Among these, Fonzies were chosen for their property to be consistently eaten by rats from their first presentation.

Experiment 1. The purpose of this experiment was to compare the effect of feeding Fonzies to rats on DA release in the PFCX and in the NAc of naive rats and in rats trained to eat Fonzies. One group of rats (Fonzies trained) was presented $2 \mathrm{gm}$ of Fonzies every day between 10 A.M. and 12 P.M. for three consecutive days; the rats were allowed to eat this food for $20 \mathrm{~min}$. The other group (Fonzies naive) was not fed Fonzies. Latency to eat and amount of Fonzies eaten were recorded on each session. The next day, rats from each group were randomly allocated to two groups. One group was implanted in the PFCX of one side whereas the other group was implanted in the NAc. As a result of this, four groups of rats were obtained: Fonzies-naive and Fonzies-trained, implanted in either the PFCX or the NAc. The next day, microdialysis was started and after stabilization of DA output, Fonzies were presented to all rats for $20 \mathrm{~min}$. When feeding started, collection of a new sample was started. Latency to eat and amount of Fonzies eaten were recorded. In one group of Fonziesnaive rats implanted in the PFCX, Fonzies were presented to the rat but were withdrawn at the first attempt to eat them. Latency to eat was recorded and DA output was monitored for $1 \mathrm{hr}$ from the presentation of Fonzies.

Experiment 2. The purpose of this experiment was to investigate the response of DA transmission in the PFCX and in the NAc to Fonzies feeding after two successive presentations of Fonzies. Two groups of Fonzies-naive rats were implanted with probes in the PFCX or in the NAc, respectively; the next day, after stabilization of DA output, rats were presented with Fonzies and allowed to eat for $20 \mathrm{~min}$. Latency to eat and amount of Fonzies eaten were also recorded. After $2 \mathrm{hr}$, Fonzies were again presented and latency to eat and amount eaten were again recorded.

Experiment 3. The purpose of this experiment was to study the recovery from habituation of feeding-induced stimulation of DA transmission in the NAc after a previous Fonzies meal. Rats were divided into three 


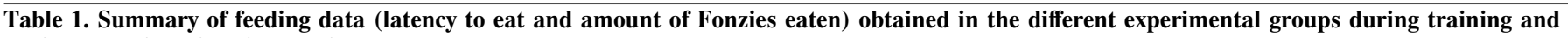
during the microdialysis experiment

\begin{tabular}{|c|c|c|c|c|c|c|c|c|c|c|}
\hline \multirow[b]{2}{*}{ Experiment } & \multirow[b]{2}{*}{ Group } & \multirow[b]{2}{*}{$n$} & \multicolumn{2}{|c|}{ First day training } & \multicolumn{2}{|c|}{ Second day training } & \multicolumn{2}{|c|}{ Third day training } & \multicolumn{2}{|c|}{ Microdialysis experiment } \\
\hline & & & Latency & Amount & Latency & Amount & Latency & Amount & Latency & Amount \\
\hline 1 & Naive & 14 & & & & & & & $8 ’ 31^{\prime \prime} \pm 30$ & $2.05 \pm 0.2 \mathrm{gm}$ \\
\hline 1 & Trained & 7 & $12^{\prime} 7^{\prime \prime} \pm 1 '$ & $0.81 \pm 0.06 \mathrm{gm}$ & $6330 ” \pm 50 ”$ & $1.23 \pm 0.1 \mathrm{gm}$ & $2 ' 10 " \pm 10 ”$ & $2.1 \pm 0.1 \mathrm{gm}$ & $19 " \pm 1 ”$ & $3.95 \pm 0.2 \mathrm{gm}$ \\
\hline 2 & First Fonzies & 11 & & & & & & & $8 ' 23 " \pm 35 ”$ & $1.95 \pm 0.1 \mathrm{gm}$ \\
\hline 2 & Second Fonzies & 11 & & & & & & & $4 " \pm 0$ & $4 \pm 0.2 \mathrm{gm}$ \\
\hline 3 & $0 \mathrm{~d}$ & 6 & & & & & & & $8 ' 45^{\prime \prime} \pm 30 ”$ & $2 \pm 0.2 \mathrm{gm}$ \\
\hline 3 & $1 \mathrm{~d}$ & 3 & $14{ }^{\prime} " \pm 1 '$ & $0.8 \pm 0.03 \mathrm{gm}$ & & & & & $15 ” \pm 0$ & $4 \pm 0.2 \mathrm{gm}$ \\
\hline 3 & $5 \mathrm{~d}$ & 4 & $14^{\prime} 45^{\prime \prime} \pm 1{ }^{\prime}$ & $0.76 \pm 0.02 \mathrm{gm}$ & & & & & $22 " \pm 1 "$ & $4.2 \pm 0.2 \mathrm{gm}$ \\
\hline 4 & Pseudoconditioned & 4 & $14^{\prime} 5^{\prime \prime} \pm 1^{\prime}$ & $0.8 \pm 0.02 \mathrm{gm}$ & $7 ’ 13 ” \pm 25 ”$ & $1.3 \pm 0.05 \mathrm{gm}$ & $2 ' 56^{\prime \prime} \pm 10^{\prime \prime}$ & $2.3 \pm 0.1 \mathrm{gm}$ & $22 " \pm 1 ”$ & $3.8 \pm 0.1 \mathrm{gm}$ \\
\hline 4 & Extinction & 4 & $14^{\prime} 20^{\prime \prime} \pm 11^{\prime}$ & $0.75 \pm 0.03 \mathrm{gm}$ & $7 ’ 20 ” \pm 30 ”$ & $1.2 \pm 0.1 \mathrm{gm}$ & $2 ’ 36 ” \pm 10 ”$ & $2.3 \pm 0.1 \mathrm{gm}$ & $19 " \pm 0$ & $3.8 \pm 0.1 \mathrm{gm}$ \\
\hline 4 and 5 & Conditioned & 10 & $14^{\prime} 36^{\prime \prime} \pm 1^{\prime}$ & $0.8 \pm 0.04 \mathrm{gm}$ & $7 ' 14^{\prime \prime} \pm 32 ”$ & $1.17 \pm 0.05 \mathrm{gm}$ & $27^{\prime \prime} \pm 10^{\prime \prime}$ & $2.18 \pm 0.1 \mathrm{gm}$ & $21 ” \pm 1 ”$ & $3.65 \pm 0.1 \mathrm{gm}$ \\
\hline 4 and 5 & Unconditioned & 4 & & & & & & & $21 " \pm 1 ”$ & $3.8 \pm 0.1 \mathrm{gm}$ \\
\hline 6 & Conditioned & 21 & $14^{\prime} 35^{\prime \prime} \pm 1 '$ & $0.8 \pm 0.05 \mathrm{gm}$ & $7 ' 10 " \pm 30 ”$ & $1.2 \pm 0.06 \mathrm{gm}$ & $2{ }^{\prime} 40^{\prime \prime} \pm 10 ”$ & $2.3 \pm 0.1 \mathrm{gm}$ & $22 " \pm 1 ”$ & $3.65 \pm 0.15 \mathrm{gm}$ \\
\hline
\end{tabular}

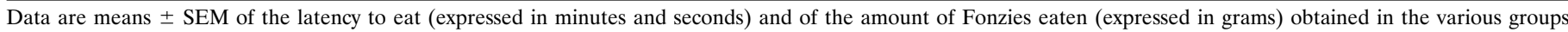
$(n=$ number of rats per group).

groups. Two groups were allowed to eat Fonzies ( $2 \mathrm{gm}$ for $20 \mathrm{~min}$ ) on either one occasion for $5 \mathrm{~d}$ or $24 \mathrm{hr}$ before the microdialysis experiment; the third group was not presented with any Fonzies. All rats were given implanted with probes in the NAc; the next day microdialysis was performed. During the microdialysis experiment, all rats were presented with $2 \mathrm{gm}$ of Fonzies and allowed to eat for $20 \mathrm{~min}$. Latency to eat and amount eaten were recorded.

Experiment 4. The purpose for this experiment was to investigate whether neutral stimuli, extrinsic to Fonzies, could be conditioned for their ability to stimulate DA transmission in the PFCX by their predictive association with Fonzies feeding. Rats were assigned to four groups: conditioned; unconditioned; pseudoconditioned; and extinction groups. The conditioned group was trained by the presentation of an empty sky-blue transparent plastic cylindrical box (height, $8 \mathrm{~cm}$; diameter, $6 \mathrm{~cm}$ ), the container of a brand of Cotton-Fiock (Cotoneve Sisma, Mantova, Italy). This object was placed in each individual cage for $40 \mathrm{~min}$ and then withdrawn to be replaced with $2 \mathrm{gm}$ of Fonzies that could be eaten for $20 \mathrm{~min}$. This association was repeated once every day for $3 \mathrm{~d}$. On the fourth day, rats were implanted with probes in the PFCX. The unconditioned group was not presented with any object before Fonzies presentation. The pseudoconditioned group was presented with the plastic box $40 \mathrm{~min}$ after the completion of Fonzies feeding. The extinction group was trained exactly as the conditioned group, but in the evening of the third day (between 3 and 6 P.M.) the plastic box was presented for $40 \mathrm{~min}$ without being reinforced by Fonzies. Incentive responses were recorded. On the morning of the fourth day, the rats were implanted with probes in the PFCX; in the evening the extinction group was again presented with the plastic box without being reinforced by Fonzies. On the morning of the fifth day, before starting microdialysis, the extinction group received the last nonreinforced presentation of the conditioned stimulus (plastic box). Incentive responses were recorded. During microdialysis, all rats were presented with the plastic box for $40 \mathrm{~min}$ and then with Fonzies, which could be eaten for $20 \mathrm{~min}$. Incentive responses to the box, latency to eat, and food eaten were recorded.

Experiment 5. The purpose of this experiment was to investigate whether DA transmission in the NAc could be conditioned in the same manner that resulted in successful conditioning of DA transmission in the PFCX. Rats were assigned to two groups, a conditioned and a unconditioned group, and were trained exactly as in Experiment 4. After training, rats were implanted in the NAc, and on the day of microdialysis were presented with the box for $40 \mathrm{~min}$, followed by Fonzies as in Experiment 4.

Experiment 6. The ability of DA in the PFCX and in the NAc to respond to a conditional stimulus intrinsic to Fonzies (e.g., smell) was investigated by training rats as in Experiment 4, except that the conditioned stimulus was provided by a plastic box (same as in Experiment 4) drilled and filled with $6 \mathrm{gm}$ of Fonzies. One group of rats was implanted in the NAc and the other in the PFCX.

Statistics. Statistical analysis was carried out by Statgraphics software (5TSC-PLUSWARE, Rockville, MD). One-way or two-way ANOVA with repeated measures over time was applied to the data obtained from the serial assays of DA after each treatment. Results from treatments showing significant overall changes were subjected to post hoc Tukey's test; it was determined that $p<0.05$ was statistically significant. Basal values were the means of three consecutive samples differing by no more than $10 \%$. One-way or two-way ANOVA and post hoc Tukey's test were also applied to the results of the behavioral observations.

\section{RESULTS}

\section{Basal dialysate DA}

Basal dialysate DA (expressed as mean \pm SEM fmol/sample) was $22 \pm 2(n=51)$ in the PFCX (20 min samples) and $80 \pm 9(n=$ $41)$ in the NAc (10 min samples).

\section{Feeding-induced release of DA in the PFCX and in the NAc of Fonzies-naive and Fonzies-trained rats (Experiment 1)}

The effect of Fonzies feeding on dialysate DA was studied in rats naive to Fonzies and in rats trained to eat Fonzies.

Table 1 shows the feeding data (latency to eat and amount of Fonzies eaten) obtained during training on Fonzies. One-way ANOVA revealed a significant effect of training on latency to eat $\left(F_{3,28}=999.990 ; p=0.001\right)$ and amount of Fonzies eaten $\left(F_{3,28}\right.$ $=414.457 ; p=0.001)$. Post hoc analysis showed that training on Fonzies resulted in a progressive decrease in latency to eat and increase in the amount of Fonzies eaten.

One-way ANOVA of feeding data during microdialysis did not reveal a significant difference among rats given implantations in the PFCX and rats implanted in the NAc as far as latency to eat Fonzies (Fonzies naive: $F_{1,13}=0.343, p=0.574$; Fonzies trained: $F_{1,6}=1.20, p=0.315$ ) and amount of Fonzies eaten (Fonzies naive: $F_{1,13}=0.807, p=0.395$; Fonzies trained: $F_{1,6}=1.27, p=$ 0.303). Therefore, feeding data from rats implanted in the PFCX and rats implanted in the NAc were collapsed into a single group.

Table 1 shows the feeding data obtained in Fonzies-naive and Fonzies-trained rats during microdialysis. Fonzies-naive rats started to eat Fonzies after a latency of $8 \mathrm{~min} 31 \mathrm{sec} \pm 30 \mathrm{sec}$, and after $20 \mathrm{~min}$ they had eaten $2.05 \pm 0.2 \mathrm{gm}$. On the other hand, Fonzies-trained rats started to eat Fonzies after $19 \mathrm{sec} \pm 1 \mathrm{sec}$ and ate a total of $3.95 \pm 0.2 \mathrm{gm}$. One-way ANOVA of the differences between Fonzies-naive and Fonzies-trained rats revealed a significant effect of group on latency to eat $\left(F_{1,21}=331.948 ; p=0.001\right)$ and amount of Fonzies eaten $\left(F_{1,21}=509.537 ; p=0.001\right)$. Post 


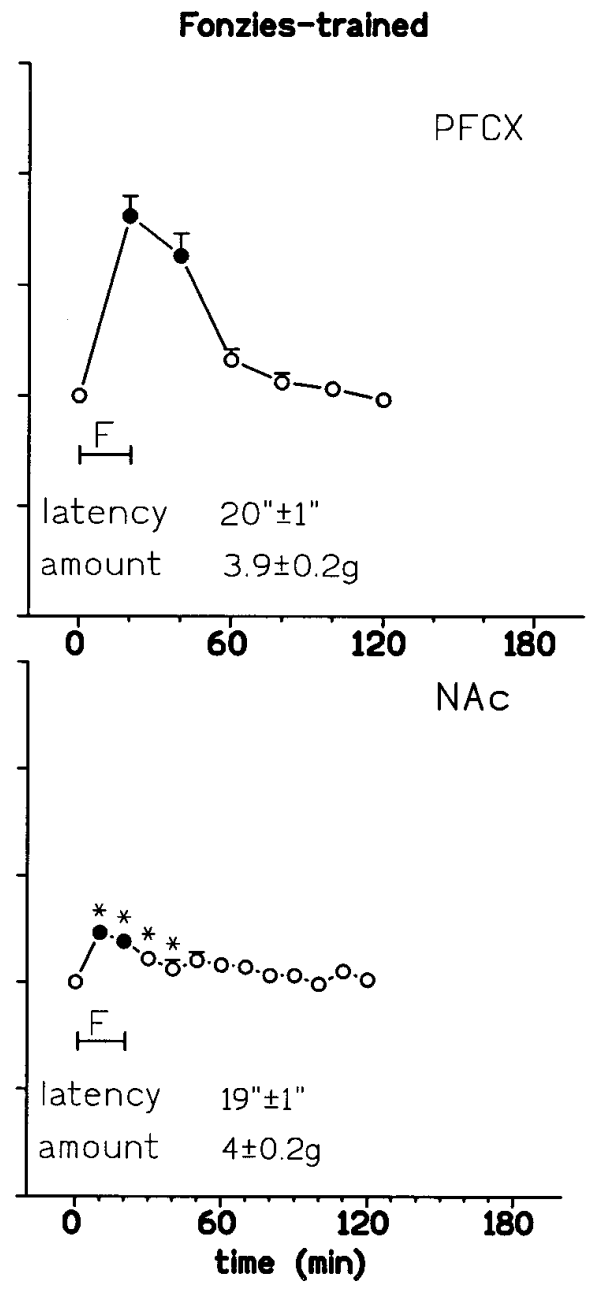

Figure 1. Effect of Fonzies feeding on DA output in dialysates from the PFCX (top) and the NAc (bottom) of Fonzies-naive and Fonzies-trained rats. Latency to eat (in seconds) and amount of Fonzies eaten (in grams) are also shown. Results are mean \pm SEM of the results obtained in at least four rats. Filled symbols, $p<0.05$ with respect to basal values; $* p<0.05$ with respect to Fonzies-naive rats.

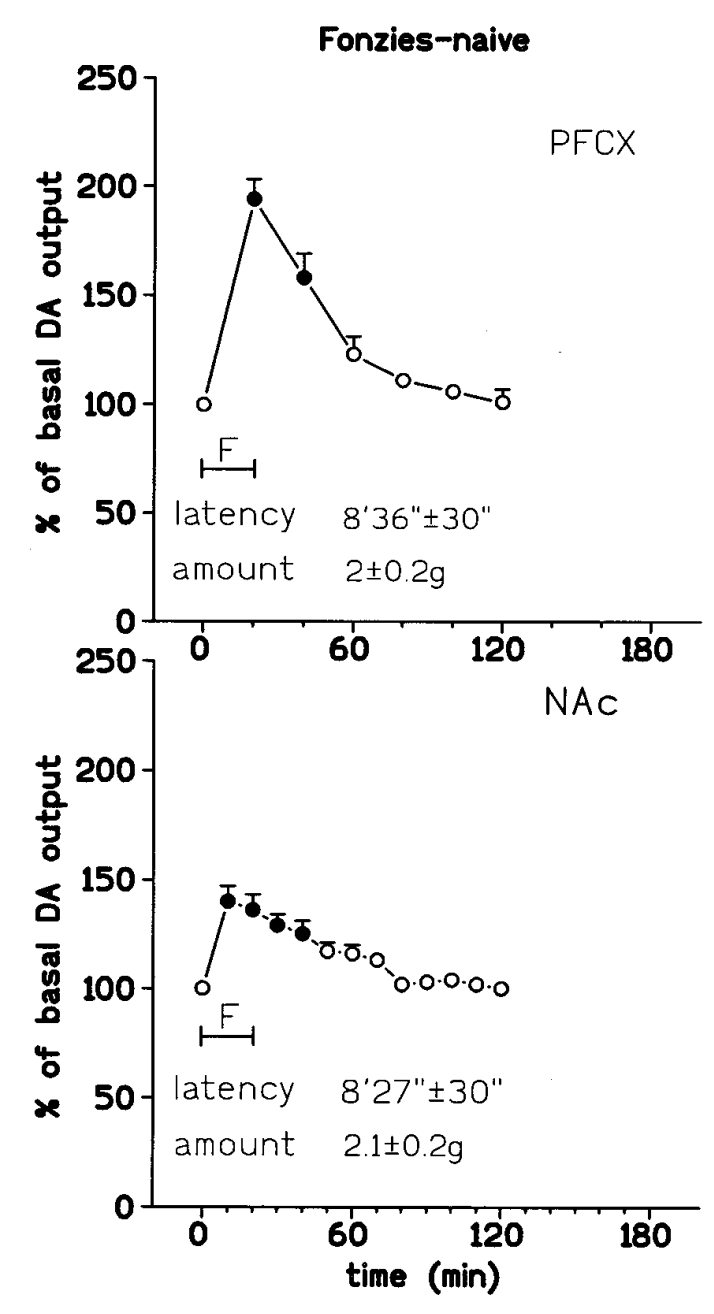

hoc analysis showed a shorter latency to eat and larger amount of food eaten in Fonzies-trained as compared with Fonziesnaive rats.

Figure 1 shows the time course of dialysate DA in the PFCX and in the NAc of Fonzies-naive and Fonzies-trained rats during feeding of Fonzies.

Two-way ANOVA of the changes of dialysate DA in the NAc of Fonzies-naive and Fonzies-trained rats revealed a significant effect of time $\left(F_{12,115}=18.169 ; p=0.001\right)$ and group $\left(F_{1,126}=\right.$ 23.174; $p=0.001)$ and a significant interaction $\left(F_{25,103}=2.349\right.$; $p=0.001)$. Post hoc analysis showed a significant time-related increase of dialysate DA in the PFCX and in the NAc of Fonziesnaive and Fonzies-trained rats. Figure 1 shows the time points where a significant increase over basal was observed. Post hoc analysis also showed that feeding of Fonzies induced a lesser increase of dialysate DA in the NAc as compared with Fonziesnaive rats. Figure 1 also shows the time points where a significant post hoc difference between Fonzies-naive and Fonzies-trained rats was obtained.

With respect to changes of dialysate DA in the PFCX, two-way ANOVA showed a significant effect of time but no significant effect of group $\left(F_{1,70}=0.543 ; p=0.472\right)$ among Fonzies-naive and Fonzies-trained rats. Figure 1 shows the time points where a significant increase over basal was observed.

To investigate whether in naive rats Fonzies presentation per se could modify dialysate DA independently from feeding, Fonzies were presented to naive rats implanted in the PFCX but were removed as soon as the rat attempted to eat. The resulting latency to approach the food was $8 \mathrm{~min} 12 \mathrm{sec} \pm 25 \mathrm{sec}$, superimposable to that obtained in Fonzies-naive rats of Figure 1. However, one-way ANOVA did not reveal a significant change in dialysate DA from the PFCX during $1 \mathrm{hr}\left(F_{4,10}=2.091\right.$; $p=0.157)$.

Histological analysis showed that the NAc probes were located in the medial part of the NAc (Fig. 2). In three rats (one in the Fonzies-naive group and two in the Fonzies-trained one) that failed to show an increase of dialysate DA after Fonzies feeding, probes were found to be located laterally in the NAc. On this basis, results from rats with probes located in the lateral NAc were excluded from calculations. PFCX probes were located in the prelimbic and infralimbic cortex.

\section{Effect of repeated Fonzies feeding on DA transmission in the PFCX and in the NAc (Experiment 2)}

To investigate further the mechanism of the influence of training on Fonzies-induced increase of dialysate DA, the effect of repeated feeding of Fonzies during the same microdialysis session was studied.

As shown in Table 1, Fonzies-naive rats implanted in the PFCX or in the NAc started to eat Fonzies after $8 \mathrm{~min} 23 \mathrm{sec} \pm 35 \mathrm{sec}$; after $20 \mathrm{~min}$ they had eaten $1.95 \pm 0.1 \mathrm{~g}$, values not dissimilar from those obtained in Experiment 1. Presentation of Fonzies $2 \mathrm{hr}$ 


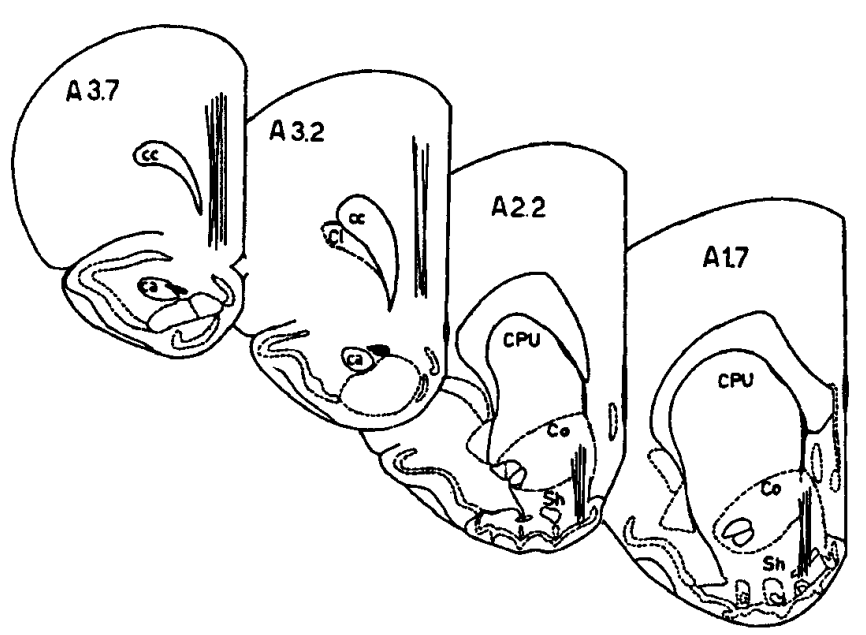

Figure 2. Schematic representation (according to Paxinos and Watson, 1987) of the areas implanted with vertical dialysis probes. Indicated is the placement of the probes of Experiment 1, the results of which are shown in Figure 1 (Fonzies-naive). $c c$, Corpus callosum; $c a$, anterior commissure; $\mathrm{Cl}$, claustrum; $\mathrm{CPU}$, caudate putamen; $\mathrm{Co}$, core; $\mathrm{Sh}$, shell of the nucleus accumbens.

later resulted in a mean latency to eat of $4 \mathrm{sec} \pm 0$ and an amount of Fonzies eaten of $4 \pm 0.2 \mathrm{gm}$. One-way ANOVA of the results obtained in the first and in the second Fonzies presentation revealed a significant effect of group on the latency to eat $\left(F_{1,18}=\right.$ 999.999; $p=0.001)$ and amount of Fonzies eaten $\left(F_{1,18}=\right.$ 999.999; $p=0.001)$. Post hoc analysis showed a decrease in latency to eat and an increase in amount of Fonzies eaten on the second presentation as compared with the first one.

Figure 3 shows the time course of the changes in dialysate DA in the PFCX and in the NAc during two successive Fonzies meals. Two-way ANOVA of the changes in dialysate DA associated to the first and to the second Fonzies meal revealed a significant effect of group in the PFCX $\left(F_{1,73}=5.133 ; p=0.027\right)$ and in the NAc $\left(F_{1,87}=81.103 ; p=0.001\right)$ and a significant group $\times$ time interaction in the NAc $\left(F_{25,63}=4.852 ; p=0.001\right)$ but not in the $\operatorname{PFCX}\left(F_{13,61}=1.210 ; p=0.31\right)$. Post hoc analysis showed a significant reduction of the effect of a second Fonzies meal on dialysate DA in the NAc but not in the PFCX. Figure 3 shows the time points where a significant difference from basal and between the two Fonzies meal was obtained. It is notable that whereas the first Fonzies meal increased dialysate DA in the NAc in five samples, the second Fonzies meal elicited a significant change only in one sample.

\section{Recovery of responsiveness of NAc DA transmission to Fonzies feeding (Experiment 3)}

To investigate further the time course of habituation of DA transmission in the NAc in response to Fonzies feeding, one group of rats was fed with Fonzies $5 \mathrm{~d}$ before the microdialysis experiment, another group was fed with Fonzies $1 \mathrm{~d}$ before, and a third group was not given any Fonzies (0 d).

Table 1 shows latency to eat and amount of Fonzies eaten in the three groups of rats. One-way ANOVA of feeding data revealed a significant difference between Fonzies naive $(0 \mathrm{~d})$ and Fonzies preexposed rats ( 1 or $5 \mathrm{~d}$ before) as far as latency to eat ( 0 vs $1 \mathrm{~d}$ : $F_{1,8}=222.44, p=0.01 ; 0$ vs $\left.5 \mathrm{~d}: F_{1,8}=216.07, p=0.001\right)$ and amount of Fonzies eaten ( 0 vs $1 \mathrm{~d}: F_{1,8}=192.53, p=0.001 ; 0$ vs $\left.5 \mathrm{~d}: F_{1,8}=201.6, p=0.001\right)$. Post hoc analysis showed a decrease in latency to eat and an increase in amount of Fonzies eaten in the
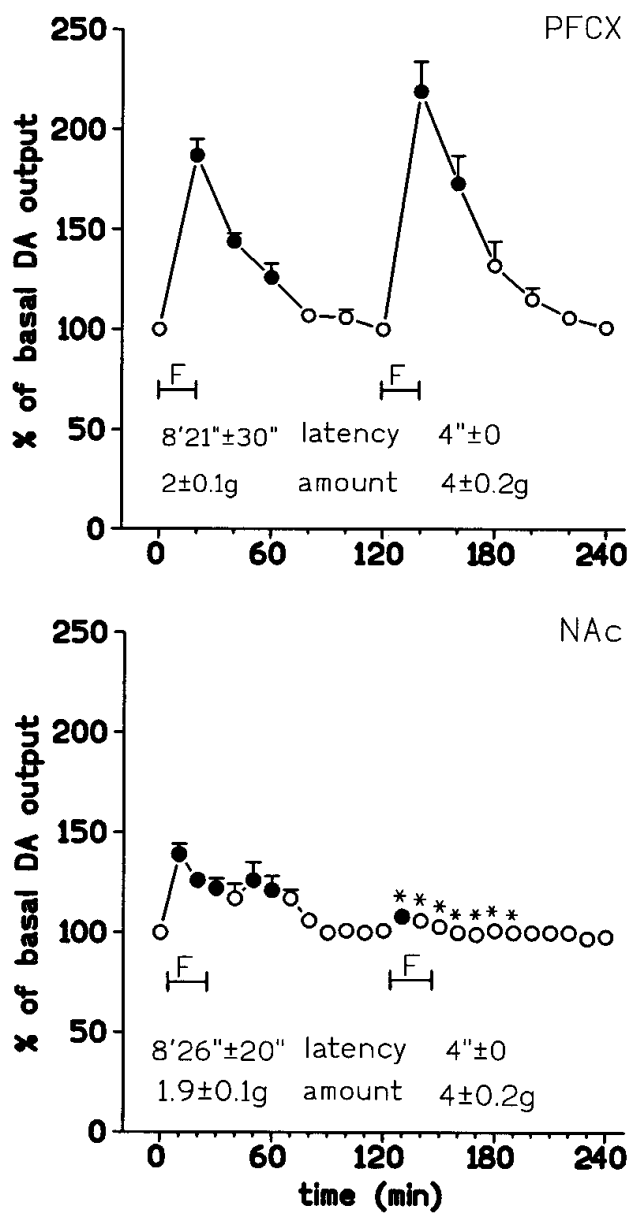

Figure 3. Effect of repeated Fonzies feeding during the same microdialysis session on DA output in dialysates from the PFCX (top) and the NAc (bottom). Latency to eat (in seconds) and amount of Fonzies eaten (in grams) are also indicated. Results are mean \pm SEM of results obtained in at least four rats. Filled symbols, $p<0.05$ with respect to basal values; $* p<0.05$ with respect to the previous Fonzies meal.

two groups previously exposed to Fonzies (1 or $5 \mathrm{~d}$ before) compared with Fonzies-naive rats. In contrast, no difference was obtained between the groups preexposed to Fonzies 1 and $5 \mathrm{~d}$ before.

Figure 4 shows the time course of dialysate DA in the NAc during Fonzies feeding in the three groups of rats. Two-way ANOVA of the changes of dialysate DA during Fonzies feeding revealed a significant effect of group $\left(F_{2,165}=62.614 ; p=0.001\right)$ and time $\left(F_{13,154}=37.812 ; p=0.001\right)$ and a significant group $\times$ time interaction $\left(F_{38,129}=6.225 ; p=0.001\right)$. Post hoc analysis showed that DA did increase over basal in Fonzies-naive rats and in rats fed on Fonzies $5 \mathrm{~d}$ before but not in those fed $1 \mathrm{~d}$ before. Figure 4 shows the time points at which an increase of dialysate DA was obtained. Post hoc analysis also showed that the change in dialysate DA in rats fed on Fonzies $1 \mathrm{~d}$ before was lower than in Fonzies-naive rats or in rats fed with Fonzies $5 \mathrm{~d}$ before.

\section{Conditioning of PFCX DA transmission to an extrinsic stimulus (Experiment 4)}

To investigate whether an otherwise neutral stimulus extrinsic to Fonzies (empty plastic box) could be conditioned for the ability to activate DA transmission in the PFCX by its predictive association with Fonzies, four groups of rats were trained: conditioned; unconditioned; pseudoconditioned; and extinction groups. 

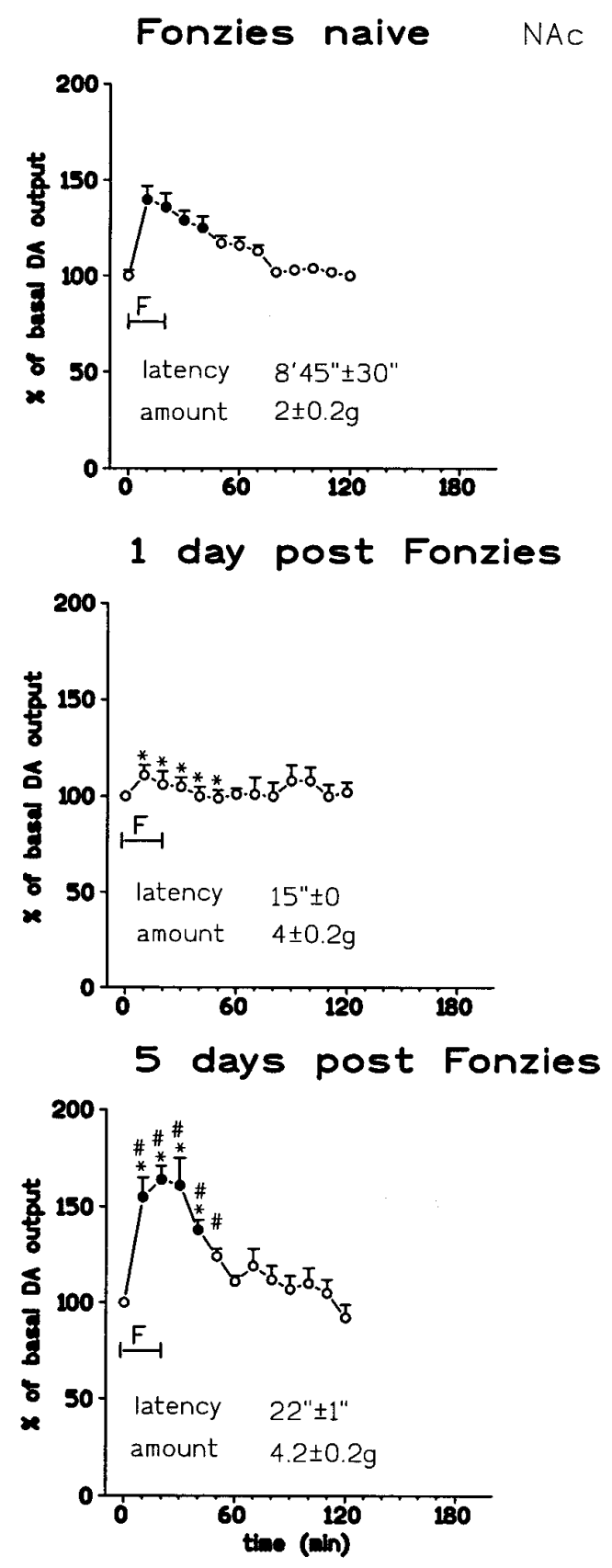

Figure 4. Effect of previous Fonzies feeding on DA output in dialysates from the NAc. Three groups were compared: naive, fed on Fonzies $1 \mathrm{~d}$ before, or fed on Fonzies $5 \mathrm{~d}$ before. Latency to eat (in seconds) and amount of Fonzies eaten (in grams) are also indicated. Results are mean \pm SEM of results obtained in at least four rats. Filled symbols, $p<$ 0.05 with respect to basal values; ${ }^{*} p<0.05$ with respect to Fonzies-naive; ${ }^{\#} p<0.05$ with respect to rats fed on Fonzies $1 \mathrm{~d}$ before the experiment.

In the extinction group, an incentive reaction was obtained in the first extinction session (score, 7), but this reaction progressively decreased in the second and third sessions (score, 0.5).

Presentation of the CS (empty box) to the conditioned group during the microdialysis experiment resulted in the expression of an incentive reaction toward the CS. Figure 5 shows the time course of incentive behavior scored in blocks of $5 \mathrm{~min}$. In the conditional group, incentive scores were maximal in the first $5 \mathrm{~min}$ after presentation of the box. Very mild ( $\leq$ score 1$)$ and short- lasting incentive reactions were obtained in the unconditioned, pseudoconditioned, and extinction groups. Two-way ANOVA showed a significant effect of group $\left(F_{3.166}=32.32 ; p=0.001\right)$ and time $\left(F_{8,161}=39.01 ; p=0.001\right)$ and a significant interaction $\left(F_{35,134}=12.91 ; p=0.001\right)$. Post hoc analysis showed a more intense incentive behavior in the conditioned group as compared with the unconditioned, pseudoconditioned, and extinction groups.

Presentation of Fonzies after the empty box resulted in short latency feeding in all four groups (conditioned, unconditioned, pseudoconditioned, and extinction). Table 1 shows the feeding data (i.e., latency to eat and amount of Fonzies eaten), which seem superimposable for the four groups.

Figure 6 shows the time course of dialysate DA from the PFCX in the four groups after sequential presentation of the CS (empty box), followed after 40 min by Fonzies.

Two-way ANOVA showed a significant effect of time $\left(F_{9,179}=\right.$ $50.151 ; p=0.001)$ and group $\left(F_{3,185}=6.29 ; p=0.001\right)$ and a significant interaction $\left(F_{39,159}=1.63 ; p=0.003\right)$. Post hoc tests showed a significant increase over basal associated to the presentation of the CS only in the conditioned group; moreover, the dialysate level of DA in the first sample taken from presentation of the CS was higher in the conditioned group than in the other three groups.

As shown in Figure 6, a significant increase of dialysate DA was obtained also in association to Fonzies feeding in all four groups. Post hoc analysis showed the feeding-induced dialysate DA increase to be significantly less in the extinguished group as compared with the conditioned and pseudoconditioned groups.

\section{Conditioning to an extrinsic stimulus and DA transmission in the NAc (Experiment 5)}

To investigate whether the same conditioned stimulus extrinsic to Fonzies was able to activate NAc DA transmission, two groups of rats, one conditioned to the empty plastic box and the other not conditioned to it, were implanted with probes in the NAc.

Presentation of the plastic box elicited incentive reactions in the conditioned but not in the unconditioned group. Comparison of the incentive actions obtained in the conditioned group of Experiment 4 (implanted in the PFCX) and of those of Experiment 5 (implanted in the NAc) showed a nonsignificant effect of group $\left(F_{1,87}=0.001 ; p=0.98\right)$, a significant effect of time $\left(F_{8,80}=56.30\right.$; $p=0.001)$ and a nonsignificant interaction $\left(F_{17,71}=0.001 ; p=1\right)$. Presentation of Fonzies resulted in feeding (scores: latency to eat and amount) not dissimilar from those of Experiment 4 (latency: $F_{1,8}=1.4, p=0.27$; amount: $F_{1,8}=2.8, p=0.13$ ).

Figure 7 shows that no significant changes in dialysate DA were obtained in response to presentation of the CS to conditioned and unconditioned rats. Thus, two-way ANOVA showed a significant effect of time $\left(F_{18,113}=24.11 ; p=0.001\right)$ but not of group $\left(F_{1,130}\right.$ $=3.92 ; p=0.051)$ and a nonsignificant interaction $\left(F_{37,92}=1.47\right.$; $p=0.12)$. Figure 7 shows that a significant increase over basal was observed in the conditioned and in the unconditioned group only after Fonzies feeding.

\section{Conditioning to a combined extrinsic-intrinsic stimulus (Experiment 6)}

To investigate further the ability of conditioned stimuli to differentially activate DA transmission in the PFCX and in the NAc, the effect of the presentation of a more salient conditioned stimulus, consisting of a perforated plastic box filled with $6 \mathrm{gm}$ of Fonzies, was studied. 


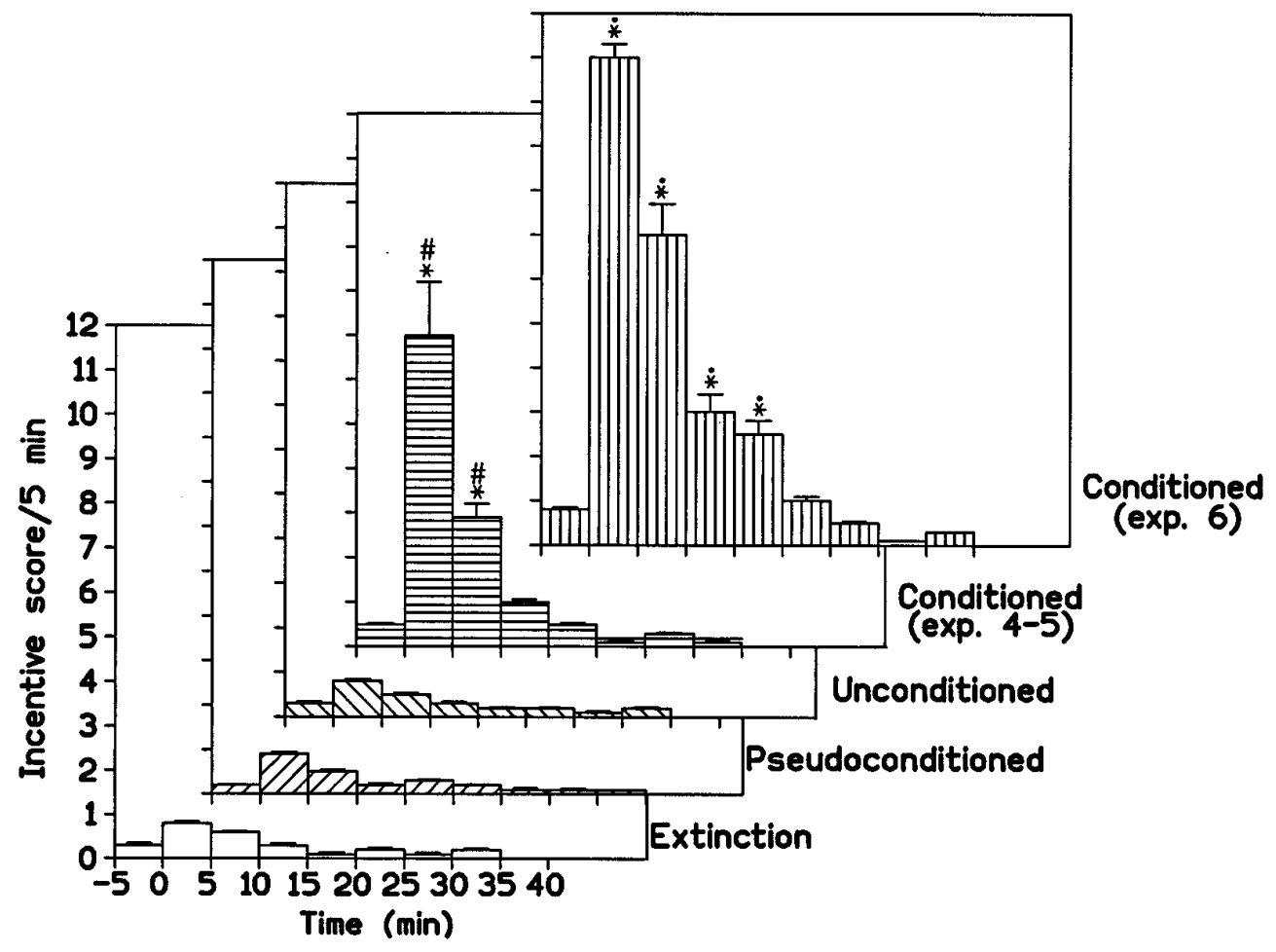

Figure 5. Time course of incentive behavior. Behavior was scored in blocks of $5 \mathrm{~min}$, after presentation of an extrinsic stimulus (empty plastic box) to rats of the conditioned, unconditioned, pseudoconditioned, and extinction groups of Experiment 5, and after presentation of a combined, intrinsic-extrinsic stimulus (Fonziesfilled plastic box) to conditioned rats of Experiment 6. Results are mean \pm SEM of results obtained in at least four rats. ${ }^{*} p<0.05$ with respect to basal values; ${ }^{*} p<0.05$ with respect to unconditioned, pseudoconditioned, and extinction. Filled symbols, $p<$ 0.05 with respect to conditioned to empty plastic box.

Presentation of Fonzies-filled box elicited strong incentive reactions (score, 11) in rats implanted in the PFCX and in rats implanted in the NAc. Comparison of incentive scores with those obtained in experiments 4 and 5 in response to presentation of an extrinsic stimulus (empty box) showed significant differences. Thus, two-way ANOVA of the incentive reaction obtained in rats implanted in the PFCX to the empty box (Experiment 4) and to Fonzies-filled box (Experiment 6) showed a significant effect of time $\left(F_{8,179}=390.85 ; p=0.001\right)$ and group $\left(F_{1,186}=169.42 ; p=0.001\right)$ and a significant interaction $\left(F_{17,170}=23.06 ; p=0.001\right)$; similarly, two-way ANOVA of the incentive reaction obtained in rats implanted in the NAc of experiments 5 (empty box) and 6 (Fonzies-filled box) showed a significant effect of time $\left(F_{8,80}=510.8 ; p=\right.$ $0.001)$ and group $\left(F_{1,87}=201.28 ; p=0.001\right)$ and a significant interaction $\left(F_{17,71}=26.4 ; p=0.001\right)$. Post hoc analysis showed the incentive score in response to Fonzies-filled box (Experiment 6) to be higher than that to the empty plastic box (Experiments 4 and 5). Presentation of Fonzies resulted in feeding scores (latency to eat and amount of Fonzies eaten; see Table 1) not different among the group implanted in the PFCX and the group implanted in the NAc (latency: $F_{1,19}=1.508$, $p=0.23$; amount: $\left.F_{1,19}=1.77, p=0.20\right)$.

Figure 8 shows the time course of dialysate DA in the PFCX and in the NAc after presentation of the CS and of Fonzies. One-way ANOVA showed a significant effect of time in the $\operatorname{PFCX}\left(F_{9,128}=\right.$ $45.55 ; p=0.001)$ and in the NAc $\left(F_{12,74}=3.68 ; p=0.001\right)$. Post hoc test showed a significant increase over basal associated to presentation of the CS in the PFCX but not in the NAc.

\section{DISCUSSION}

The main findings of the present study can be summarized as follows: phasic responsiveness of DA transmission to food and food-associated stimuli is differentially susceptible to habituation and conditioning in the NAc as compared with the PFCX.

\section{Differential influence of habituation on accumbal versus prefrontal DA}

The present study shows that in rats fed ad libitum with standard food, feeding of a novel, palatable food (Fonzies) elicits an immediate increase of extracellular DA in the PFCX and in the NAc, but this effect is severely blunted selectively in the NAc by a previous Fonzies meal. A role of satiety is excluded by the fact that blunting of NAc DA transmission was associated with a reduction in the latency to eat and an increase in the amount of Fonzies eaten. Therefore, after stimulus preexposure, a form of habituation, defined as a decrease in response to a repetitive stimulus (Thompson and Spencer, 1966), differentially affects mesolimbic as compared with mesocortical DA transmission.

Recovery from habituation was complete after $5 \mathrm{~d}$ but was slow because the reactivity of mesolimbic DA transmission was still depressed $24 \mathrm{hr}$ and $48 \mathrm{hr}$ after the last Fonzies meal. These results indicate that novelty, either absolute or relative, is important for activation of mesolimbic DA transmission by unconditioned food stimuli in a nondeprived condition.

In nondeprived rats trained to consume a palatable diet, Wilson et al. (1995) obtained a small $(+20 \%)$ and delayed increase of extracellular DA in the NAc, whereas Cenci et al. (1992) observed an increase of extracellular DA in the PFCX but not in the NAc. On the basis of our results, this blunted response of NAc DA transmission to feeding is likely to be the result of an habituation state.

\section{Differential influence of conditional stimuli on accumbal versus prefrontal DA}

Repeated predictive association of otherwise neutral stimuli to feeding of Fonzies results in acquisition by the neutral stimulus of the ability to increase DA in dialysates from the PFCX. Neutral stimuli could be either extrinsic to the reward (empty plastic box) or combined extrinsic-intrinsic (Fonzies-filled plastic box).

These results can be interpreted in the framework of classic 

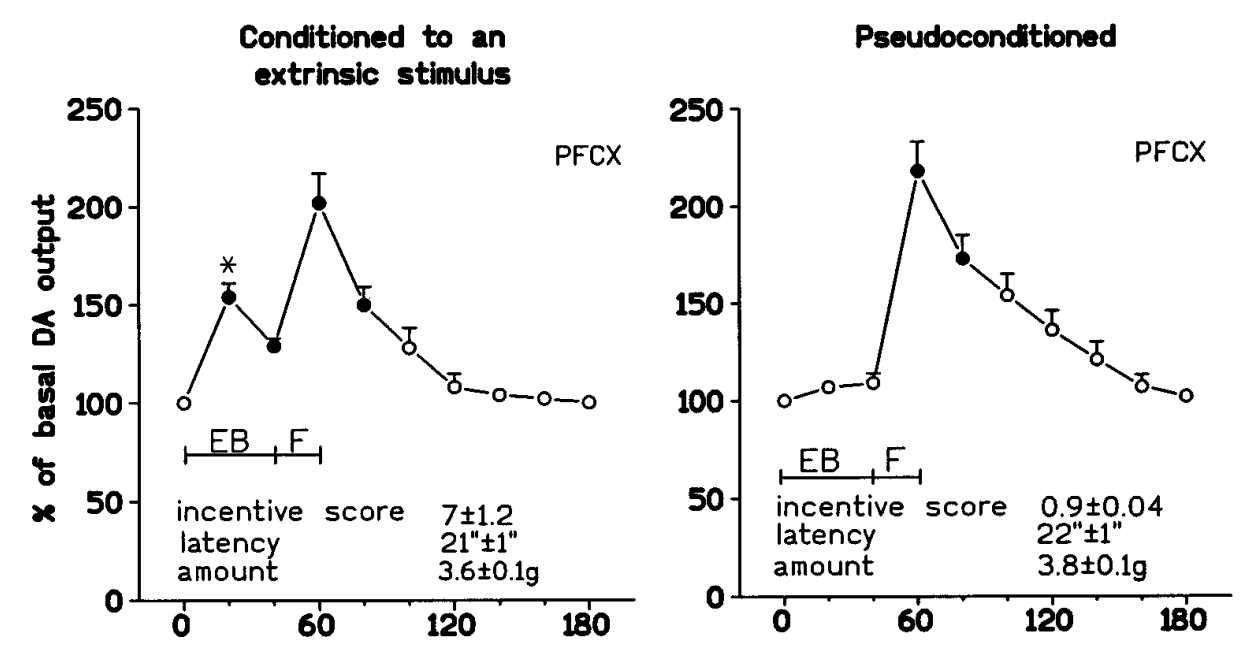

Figure 6. Effect of presentation of a conditioned extrinsic stimulus (empty plastic box) and of Fonzies feeding on DA output in dialysates from the PFCX. Four groups were compared: conditioned, unconditioned, pseudoconditioned, and extinction. Incentive score, latency to eat, and amount of Fonzies eaten are also indicated. Results are mean \pm SEM of results obtained in at least four rats. Filled symbols, $p<0.05$ with respect to basal values; ${ }^{*} p<0.05$ with respect to the unconditioned, pseudoconditioned, and extinction groups.
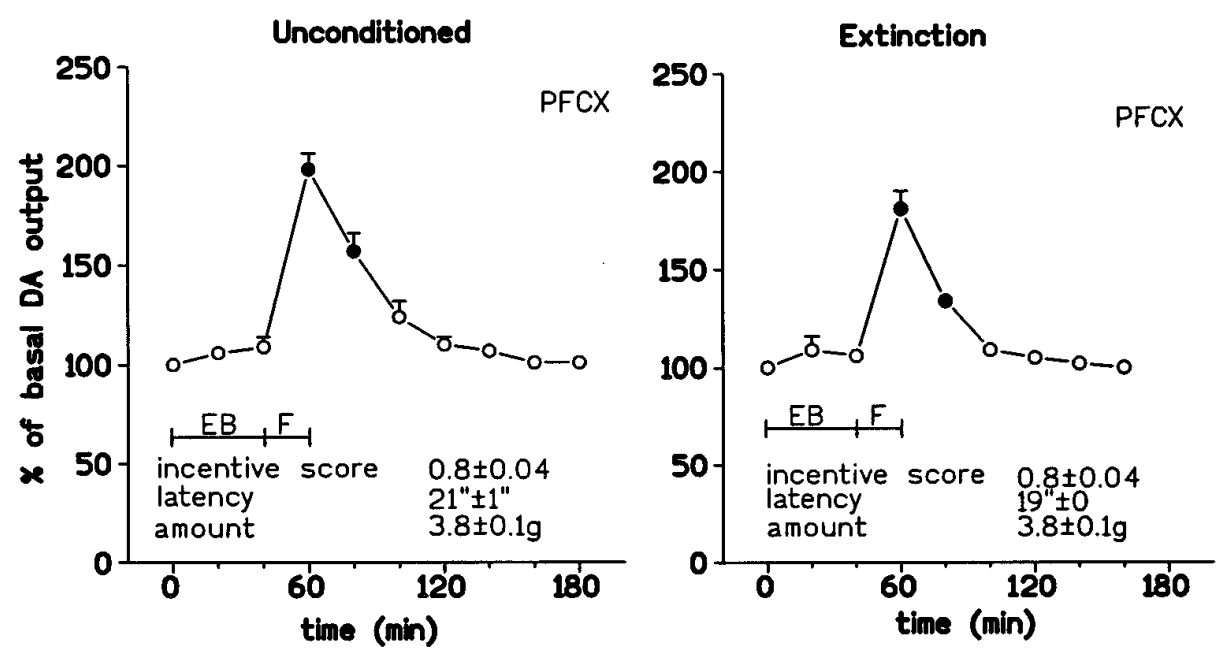

Pavlovian conditioning. Accordingly, Fonzies taste stimuli act as the unconditioned stimulus (UCS) to elicit an unconditioned response (UCR) consisting of an increase in dialysate DA. Otherwise neutral stimuli (plastic box, Fonzies smell) predictively associated with the UCS, become conditioned stimuli (CS) as they acquire the property of eliciting a conditioned response (CR) that mimicks the UCR (increase of dialysate DA in the PFCX). Consistent with this interpretation is the observation that if the to-be-conditioned stimulus does not predict the UCS but follows it as in the pseudoconditioned group, or if the CS is consistently nonreinforced, as in the extinction group, its presentation fails to elicit a CR (i.e., to increase PFCX DA).

Conditional stimuli that increased DA in the PFCX failed to affect extracellular DA in the NAc. This applies not only to an extrinsic stimulus (empty plastic box) but also to a combined extrinsic-intrinsic stimulus (Fonzies-filled plastic box). Therefore, under our conditions, conditional food stimuli differentially affect DA transmission in the PFCX and in the NAc. This differential effect, as well as the fact that a 10 min sampling was used in the NAc instead of the 20 min sampling used in the PFCX, tends to rule out factors related to the resolving power of the microdialysis technique as the reason for the lack of significant changes in the NAc after conditional food stimuli.

Conditional changes in extracellular DA in the NAc have been reported after stimuli predictive of strongly aversive ones like electrical shock or lithium (Mark et al., 1991; Young et al., 1993; Saulskaya and Marsden, 1995) or, in the case of appetitive stimuli, under food-deprivation conditions (Phillips et al., 1993; Wilson et al., 1995) but not under ad libitum conditions (Wilson et al., 1995). This suggests that conditional stimuli can activate mesolimbic DA transmission, but this depends on the type of stimulus used and on the motivational state. In the studies by Schultz et al. (1993), not all food-related stimuli but only those unique for correct execution of a task for food were able to activate the firing of DA units in the monkey mesencephalon. Unfortunately, direct comparison between our in vivo microdialysis studies at terminal DA areas and the studies of Schultz et al. (1993) is made difficult by the failure of these authors to identify the exact site of termination in the forebrain of the units recorded extracellularly in the mesencephalon and to distinguish among mesolimbic and mesocortical DA units. Other differences regard the short duration of the conditional stimulus used $(<500 \mathrm{msec})$ as well as the nature of the changes recorded (extracellular firing activity) by Schultz et al. (1993), which cannot be equated to changes in neurotransmitter release.

From the present results and those of the literature, we conclude that mesolimbic DA neurons do not code for generic motivational significance (motivational salience) but only for specific stimuli provided of a particularly high motivational impact related to their novelty, aversiveness, or occurrence under a 

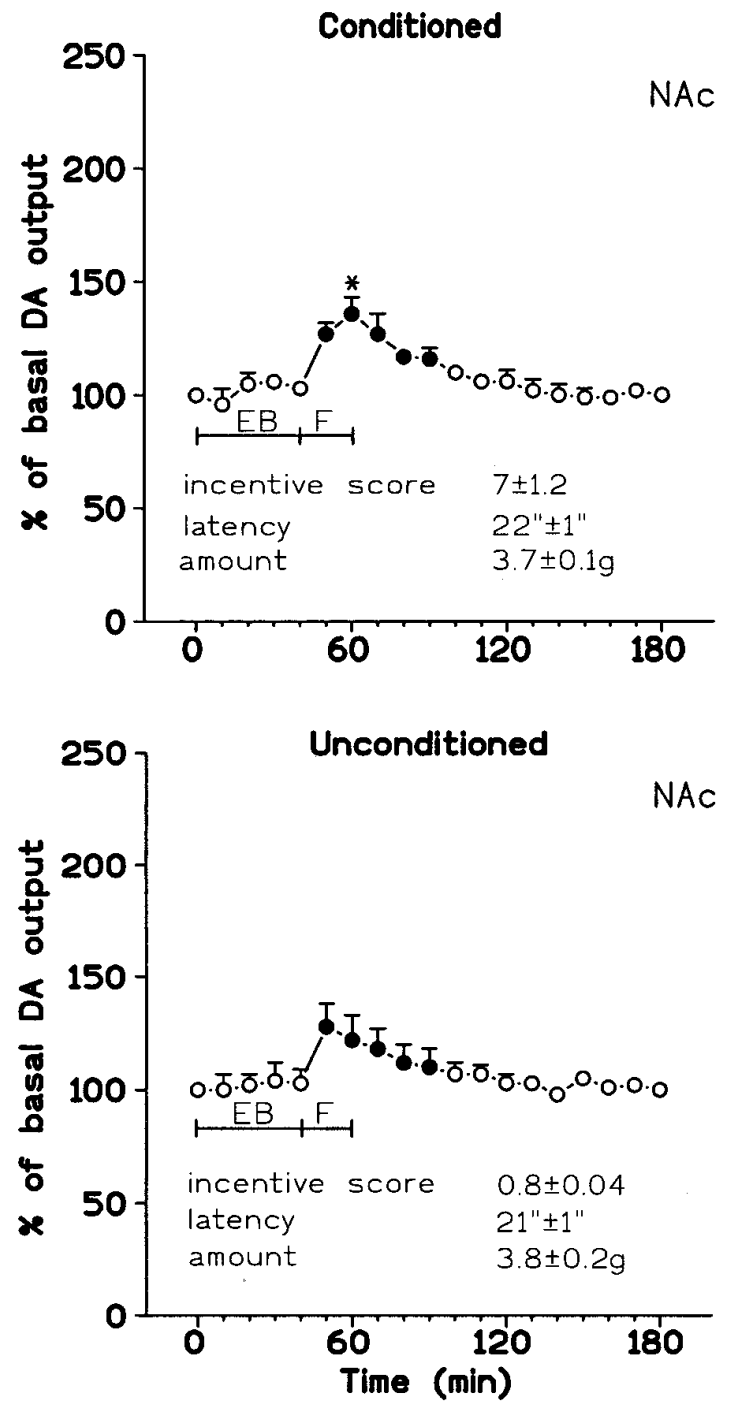

Figure 7. Effect of Fonzies feeding on DA output in dialysates from the NAc of conditioned and unconditioned rats. Incentive score, latency to eat (in seconds), and amount of Fonzies eaten are also indicated. Results are mean \pm SEM of results obtained in at least four rats. Filled symbols, $p<$ 0.05 with respect to basal values; ${ }^{*} p<0.05$ with respect to unconditioned.

deprivation state. This conclusion is at variance with the view that mesolimbic DA neurons code for generic motivational salience (Robinson and Berridge, 1993; Berridge, 1996). Such property belongs, eventually, to mesocortical DA neurons.

\section{Differential role of phasic mesolimbic and mesocortical DA transmission in the expression of incentive motivation}

In the present study, incentive behavior was recorded in parallel to dialysate DA in the PFCX and in the NAc with the precise intent to investigate the relationship between phasic DA transmission and behavioral expression of incentive motivation (Bindra, 1974; Bolles, 1975). Although a generic role of DA in the expression of incentive responses has been hypothesized by various authors (for review, see Di Chiara, 1995), Robinson and Berridge (1993) and Berridge (1996) have explicitly posited that phasic activation of DA transmission in the ventral striatum (which includes the NAc) by conditioned stimuli is instrumental for the expression of incentive responses through the mechanism
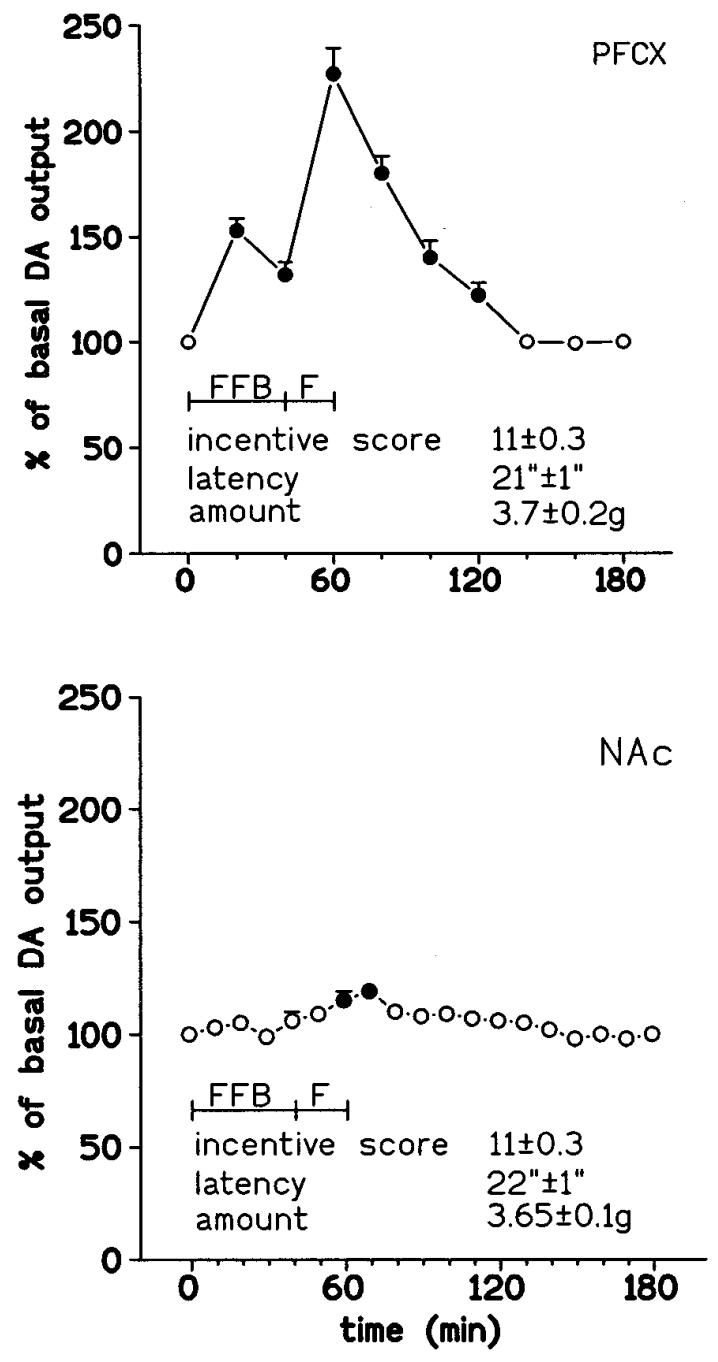

Figure 8. Effect of presentation of a conditioned combined (intrinsicextrinsic) stimulus (Fonzies-filled plastic box) and of Fonzies feeding on DA output in dialysate from the PFCX (top) and the NAc (bottom). Incentive score, latency to eat, and amount of Fonzies eaten are also indicated. Results are mean \pm SEM of results obtained in at least four rats. Filled symbols, $p<0.05$ with respect to basal values.

of "incentive salience attribution." According to this hypothesis, stimuli that have acquired motivational significance (salience) by a process of associative learning would phasically stimulate ventral striatal DA transmission; such activation, in turn, would transduce their conditional emotional properties into an incentive response. It is notable that, according to this hypothesis, DA is not involved in the associative learning process but only in the transduction of emotion into action, much like the role attributed previously to the NAc (but not necessarily to DA) by Mogenson (1987). In contrast with the hypothesis of Robinson and Berridge (1993) and of Berridge (1996), however, conditioned stimuli, either extrinsic (empty plastic box) or combined extrinsic-intrinsic (Fonzies-filled plastic box) failed to increase dialysate DA in the NAc despite their ability to elicit strong incentive responses (even more so in the case of the combined stimulus). According to our results, therefore, generic motivational salience activates mesocortical DA but is insufficient, per se, to activate mesolimbic DA transmission. Even the stimulation of mesocortical DA transmission was not directly proportional to the intensity of the incentive 
response (Experiments 4-6), suggesting that conditional stimuli trigger the activation of mesocortical DA but do not directly depend for their incentive properties on this activation.

These results are apparently in contrast with the evidence showing that blockade of NAc DA transmission by neuroleptics impairs incentive responses (Blackburn et al., 1987) and secondary reinforcement (Phillips and Fibiger, 1979; Gray and Wise, 1980). The effects of neuroleptics, however, might reflect an impairement of tonic rather than phasic activity of mesolimbic DA transmission (Grace, 1991; Di Chiara, 1995). Assuming that a normal degree of tonic DA transmission is essential for fast excitatory neurotransmission in the striatum (Di Chiara et al., 1994) it is conceivable that reduction of normal DA tone in the NAc by acute pharmacological blockade of DA transmission would result in an impairement of fast excitatory non-DA transmission in that area, with impairment of the expression of incentive responding and secondary reinforcement.

Because preparatory (i.e., appetitive) behavior takes place in response to conditioned incentive stimuli, our results tend to exclude that phasic mesolimbic DA transmission is essential for its expression, in agreement with Fibiger (1993); at variance with this author, however, we maintain that phasic activation of mesolimbic DA is not necessary for the expression of consummatory behavior. In fact, recent preexposure to Fonzies (Experiments 1-3), although facilitating consummatory behavior as estimated from the amount of Fonzies eaten, blunts the DA response in the NAc.

\section{$A$ role of mesolimbic DA in acquisition and maintenance of incentive motivation (motivational learning)?}

The present results show that although mesolimbic and mesocortical DA transmission are both activated by unconditioned food stimuli, they are differentially affected by associative (conditioning) and nonassociative (habituation) learning processes (Kupfermann, 1985), which result from repeated presentation of the primary stimulus itself (habituation) or associated neutral stimuli (conditioning). Thus, learning about the stimulus, although reducing the responsiveness of mesolimbic DA transmission (habituation), amplifies that of mesocortical DA transmission, extending it to predictive stimuli (conditioning).

These properties are consistent with an involvement of phasic mesolimbic DA transmission in the acquisition and maintenance of incentive motivation (motivational learning) but not in its expression. We hypothesize that DA release in the NAc in response to a novel or relatively novel primary stimulus enables the association between the affective properties of the stimulus and the discriminative properties of stimuli and responses that are temporally associated to it in a predictive manner. Through this process, discriminative stimuli would gain control over attentional and motor resources involved in approach behavior in response to biologically relevant stimuli; this motivational learning process would result in acquisition by the novel stimulus or maintenance by the relatively novel one of the property to activate mesocortical DA neurons and to elicit incentive responses.

\section{REFERENCES}

Abercrombie ED, Keefe KA, DiFrischia DS, Zigmond MJ (1989) Differential effect of stress on in vivo dopamine release in striatum, nucleus accumbens, and medial frontal cortex. J Neurochem 52:1655-1658.

Bassareo V, Tanda G, Petromilli P, Giua C, Di Chiara G (1996) Nonpsychostimulant drugs of abuse and anxiogenic drugs activate with differential selectivity dopamine transmission in the nucleus accumbens and in the medial prefrontal cortex of the rat. Psychopharmacology 124:293-299.
Beninger RJ (1983) The role of dopamine in locomotor activity and learning. Brain Res Rev 6:173-196.

Berger B, Gaspar P, Verney C (1991) Dopaminergic innervation of the cerebral cortex: unexpected differences between rodents and primates. Trends Neurosci 14:21-27.

Berridge KC (1996) Food reward: brain substrates of wanting and liking. Neurosci Biobehav Rev 20:1-25.

Bindra D (1968) Neuropsychological interpretation of the effects of drive and incentive-motivation on general activity and instrumental behavior. Psychol Rev 75:1-22.

Bindra D (1974) A motivational view of learning, performance and behavior modification. Psychol Rev 81:199-213.

Björklund A, Lindvall O (1984) Dopamine containing systems in the CNS. In: Handbook of chemical neuroanatomy, Vol 2, Part I, Classical transmitters in the CNS (Björklund A, Hökfelt T, eds), pp 55-122. Amsterdam: Elsevier.

Blackburn JR, Phillips AG, Fibiger HC (1987) Dopamine and preparatory behavior. I. Effects of pimozide. Behav Neurosci 101:352-360.

Blackburn JR, Phillips AG, Jakubovic A, Fibiger HC (1989) Dopamine and preparatory behavior. II. A neurochemical analysis. Behav Neurosci 103:15-23.

Bolles RC (1975) Theory of motivation, 2nd Ed. New York: Harper.

Bradberry CW, Lory JD, Roth RH (1991) The anxiogenic $\beta$-carboline FG 7142 selectively increases dopamine release in rat prefrontal cortex as measured by microdialysis. J Neurochem $56: 748-752$.

Cenci MA, Kalén P, Mandel RJ, Björklund A (1992) Regional differences in the regulation of dopamine and noradrenaline release in medial frontal cortex, nucleus accumbens and caudate-putamen: a microdialysis study in the rat. Brain Res 581:217-228.

Church WH, Justice Jr JB, Neill DB (1987) Detecting behaviorally relevant changes in extracellular dopamine with microdialysis. Brain Res 412:397-399.

D'Angio M, Scatton B (1989) Feeding or exposure to food odors increases extracellular DOPAC levels (as measured by in vivo voltammetry) in the prefrontal cortex of food-deprived rats. Neurosci Lett 96:223-228.

Di Chiara G (1990) In vivo brain dialysis of neurotransmitters. Trends Pharmacol Sci 11:116-121.

Di Chiara G (1995) The role of dopamine in drug abuse viewed from the perspective of its role in motivation. Drug Alcohol Depend 38:95-137.

Di Chiara G, Morelli M, Consolo S (1994) Modulatory functions of neurotransmitters in the striatum: ACh/dopamine/NMDA interactions. Trends Neurosci 17:228-238.

Di Chiara G, Tanda G, Frau R, Carboni E (1993) On the preferential release of dopamine in the nucleus accumbens by amphetamine: further evidence obtained by vertically implanted concentric dialysis probes. Psychopharmacology 112:398-402.

Fibiger HC (1993) Mesolimbic dopamine: an analysis of its role in motivated behavior. Semin Neurosci 5:321-327.

Grace AA (1991) Phasic versus tonic dopamine release and the modulation of dopamine system responsivity: a hypothesis for the etiology of schizophrenia. Neuroscience 41:1-24.

Gray T, Wise RA (1980) Effects of pimozide on lever-pressing behavior maintained on an intermittent reinforcement schedule. Pharmacol Biochem Behav 12:931-935.

Hernandez L, Hoebel BG (1988a) Food reward and cocaine increase extracellular dopamine in the nucleus accumbens as measured by microdialysis. Life Sci 42:1705-1712.

Hernandez L, Hoebel BG (1988b) Feeding and hypothalamic stimulation increase dopamine turnover in the accumbens. Physiol Behav 44:599-606.

Hernandez L, Hoebel BG (1990) Feeding can enhance dopamine turnover in the prefrontal cortex. Brain Res Bull 25:975-979.

Hill RT (1970) Facilitation of conditioned reinforcement as a mechanism of psychomotor stimulation. In: Amphetamine and related compounds (Costa E, Garattini S, eds), pp 781-795. New York: Raven.

Imperato A, Puglisi-Allegra S, Casolini P, Zocchi A, Angelucci L (1989) Stress-induced enhancement of dopamine and acetylcholine release in limbic structures: role of corticosterone. Eur J Pharmacol 165:337-338.

Kissinger PT, Hart JB, Adams RN (1973) Voltammetry in brain tissue: a new physiological measurement. Brain Res 55:209-213.

Kupfermann I (1985) Learning and Memory. In: Principles of neural science (Kandel ER, ed), pp 997-1008. Amsterdam: Elsevier.

Inoue K, Kiriike N, Okuno M, Ito H, Fujisaki Y, Matsui T, Kawakita Y 
(1993) Scheduled feeding caused activation of dopamine metabolism in the striatum of rats. Physiol Behav 53:177-181.

Le Moal M, Simon H (1991) Mesocorticolimbic dopaminergic network: functional and regulatory roles. Physiol Rev 71:155-234.

Mark GP, Blander DS, Hoebel BG (1991) A conditioned stimulus decreases extracellular dopamine in the nucleus accumbens after the development of a learned taste aversion. Brain Res 551:308-310.

Marsden CA, Brazell MP, Maidment NT (1984) An introduction to in vivo electrochemistry. In: Measurement of neurotransmitter release in vivo Chap 6 (Marsden CA, ed), New York: Wiley.

Miller JD, Sanghera MK, German DC (1981) Mesencephalic dopaminergic unit activity in the behaviorally conditioned rat. Life Sci 29:1255-1263.

Mirenowicz J, Schultz W (1996) Preferential activation of midbrain dopamine neurons by appetitive rather than aversive stimuli. Nature 379:449-451.

Mogenson GJ (1987) Limbic-motor integration. In: Progress in psychobiology and phsysiological psychology (Epstein AN, Morris A, eds), pp 117-170. New York: Academic.

Paxinos G, Watson C (1987) The rat brain in stereotaxic coordinates. 2nd Ed. London: Academic.

Phillips AG, Fibiger HC (1979) Decreased resistance to extinction after haloperidol: implication for the role of dopamine in reinforcement. Pharmacol Biochem Behav 10:751-761.

Phillips AG, Pfaus JG, Blaha CD (1991a) Dopamine and motivated behavior: insights provided by in vivo analysis. In: The mesolimbic dopamine system: from motivation to action (Willner P, Scheel-Krüger J, eds), pp 199-224. Chichester, UK: Wiley.

Radhakishun FS, Van Ree JM, Westerink HBC (1988) Scheduled eating increases dopamine release in the nucleus accumbens of food-deprived rats as assessed with on-line brain microdialysis. Neurosci Lett 85:351-356.

Robinson TE, Berridge KC (1993) The neural basis of drug craving: an incentive-sensitization theory of addiction. Brain Res Rev 18:247-291.

Robbins TW, Cador M, Taylor JR, Everitt BJ (1989) Limbic-striatal interactions in reward-related processes. Neurosci Biobehav Rev $13: 155-162$

Salamone JD (1992) Complex motor and sensorimotor functions of striatal and accumbens dopamine: involvement in instrumental behavior processes. Psychopharmacology 107:160-174.

Saulskaya N, Marsden CA (1995) Conditional dopamine release: dependence upon $N$-methyl-D-aspartate receptors. Neuroscience 67:57-63.

Schultz W (1992) Activity of dopamine neurons in the behaving primate. Neuroscience 4:129-138.

Schultz W, Apicella P, Ljungberg T (1993) Responses of monkey dopa- mine neurons to reward and conditioned stimuli during successive steps of learning a delayed response task. J Neurosci 13:900-913.

Stamford JA (1986) In vivo voltammetry: some methodological considerations. J Neurosci Methods 17:1-29.

Steinfels GF, Heym J, Jacobs BL (1981) Single unit activity of dopaminergic neurons in freely moving animals. Life Sci 29:1435-1442.

Tanda G, Bassareo V, Di Chiara G (1996) Mianserin markedly and selectively increases extracellular dopamine in the prefrontal cortex as compared to the nucleus accumbens of the rat. Psychopharmacology 123:127-130.

Thierry AM, Blanc G, Sobel A, Stinus L, Glowinski J (1973) Dopaminergic terminals in the rat cortex. Science 182:499-501.

Thierry AM, Tassin JP, Blanc G, Glowinski J (1976) Selective activation of mesocortical dopaminergic system by stress. Nature 263:242-244.

Thompson RF, Spencer WA (1966) Habituation: a model phenomenon for the study of neuronal substrates of behavior. Psychological Rev 73:16-43.

Ungerstedt U (1984) Measurements of neurotransmitter release by intracranial dialysis. In: Measurement of neurotransmitter release in vivo (Marsden CA, ed), pp 81-105, Chichester, UK: Wiley.

Westerink BHC (1996) Brain microdialysis and its application for the study of animal behavior. Behav Brain Res 70:103-124.

Westerink BHC, Damsma G, Rollema H, DeVries JB, Horn AS (1987) Scope and limitations of in vivo brain dialysis: a comparison of its application to various neurotransmitter systems. Life Sci 41:1763-1776.

Westerink BHC, Teisman A, de Vries JB (1994) Increase in dopamine release from the nucleus accumbens in response to feeding: a model to study interactions between drugs and naturally activated dopaminergic neurons in the rat brain. Naunyn Schmiedebergs Arch Pharmacol 349:230-235.

Wilson C, Nomikos GC, Collu M, Fibiger HC (1995) Dopaminergic correlates of motivated behavior: importance of drive. J Neurosci 15:5169-5178.

Wise RA (1982) Neuroleptics and operant behavior: the anhedonia hypothesis. Behav Brain Sci 5:39-87.

Yoshida M, Yokoo H, Mizoguchi K, Kawahara H, Tsuda A, Nishikawa T, Tanaka M (1992) Eating and drinking cause increased dopamine release in the nucleus accumbens and ventral tegmental area in the rat: measurement by in vivo microdialysis. Neurosci Lett 139:73-76.

Young AMJ, Joseph MH, Gray JA (1992) Increased dopamine release in vivo in nucleus accumbens and caudate nucleus of the rat during drinking: a microdialysis study. Neuroscience 48:871-876.

Young AMJ, Joseph MH, Gray JA (1993) Latent inhibition of conditioned dopamine release in the nucleus accumbens. Neuroscience 54:5-9. 